\title{
$\begin{array}{lllllll}\text { A } & \mathbf{R} & \mathbf{T} & \mathbf{I} & \mathbf{C} & \mathbf{L} & \mathbf{E}\end{array}$
}

\section{User-Centered Design and Interactive Health Technologies for Patients}

\author{
ANNETTE DE VITO DABBS, RN, PhD \\ BRAD A. MYERS, PhD \\ KENNETH R. MC CURRY, MD \\ JACQUELINE DUNBAR-JACOB, RN, PhD \\ ROBERT P. HAWKINS, PhD \\ ALEX BEGEY, BS \\ MARY AMANDA DEW, PhD
}

The development of interactive health technologies (IHTs) to promote health and manage illness has led to fundamental changes in health practices ${ }^{1}$; in fact, these technologies have been credited with transforming healthcare. ${ }^{2,3}$ Interactive health technologies are defined as the interaction of an individual-consumer, patient, caregiver, or professional-with a computerized technology to access, monitor, share, or transmit health information ${ }^{4}$ and refer specifically to the communication and software programs for users, rather than the platforms (desktop computers, Internet, handheld computers, or other devices) that run or deliver these applications. These applications support activities such as exchanging health information among patients and between patients and professionals, enabling health decision making, and promoting positive health behaviors such as self care. ${ }^{4-6}$ IHTs have been successful in promoting better health outcomes for diverse patient populations. Examples include the Comprehensive Health Enhancement Support System, a computer-based system of integrated services designed to help individuals cope with a health crisis or medical concern ${ }^{7}$; HeartCare, an Internet-based information and support system for patients recovering after coronary artery bypass surgery ${ }^{8}$; and Partners in School Asthma Management for inner-city elementary school children. ${ }^{9}$

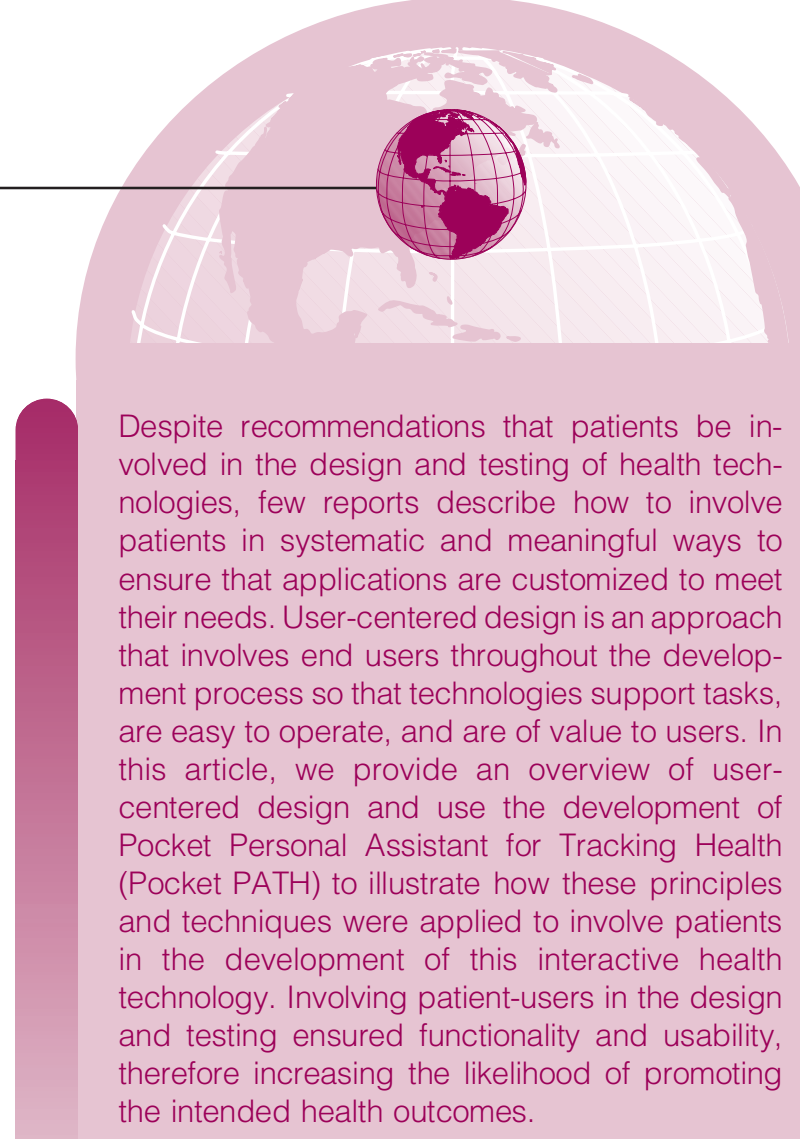

KEYWOR D S

Handheld computers • Interactive health technologies • Lung transplantation $\cdot$ Self-monitoring • User-centered design

However, descriptions of IHTs intended for use by patients are typically limited to reporting their efficacy in promoting health behaviors and outcomes. It is rare to find reports describing how these IHTs were actually developed, particularly the methods that were used to involve patients in the early stages to design and test their usability. However, for those who are considering

Author Affiliations: School of Nursing, University of Pittsburgh, PA (Drs Dabbs and Dunbar-Jacob and Mr Begey); Human Computer Interaction Institute, School of Computer Science, Carnegie Mellon University, Pittsburgh, PA (Dr Myers); Department of Thoracic and Cardiovascular Surgery, Cleveland Clinic, $\mathrm{OH}$ (Dr Mc Curry); School of Journalism and Mass Communication, University of Wisconsin, Madison (Dr Hawkins); and Departments of Psychiatry, Psychology, and Epidemiology, School of Medicine, University of Pittsburgh, PA (Dr Dew).

Funding sources for this project included the following: National Institutes of Health K 01 NR 009385, University of Pittsburgh School of Nursing Center for Research and Evaluation Pilot Funding Program, and the Central Research Development Fund of the University of Pittsburgh.

Corresponding author: Annette De Vito Dabbs, RN, PhD, Acute and Tertiary Care, School of Nursing, University of Pittsburgh, 3500 Victoria St, Pittsburgh, PA 15261 (ajdst42@pitt.edu). 
developing IHTs, knowledge of these steps is crucial if the applications are to meet the patients' needs, are easy to learn, and effectively support their tasks. Furthermore, despite recommendations that patients be involved in the design and testing of health technologies ${ }^{10}$ and that a full description of how IHTs were designed, tested, and debugged be included in reports about such applications, ${ }^{11}$ few reports describe how to involve patients in systematic and meaningful ways throughout the development process. Therefore, the purposes of this report were to (1) review the principles of usercentered design (UCD), (2) illustrate how to involve patients in UCD and prototype testing, and (3) conduct a descriptive, pilot study to determine whether the Pocket Personal Assistant for Tracking Health (Pocket PATH [University of Pittsburgh, Pittsburgh, PA]) meets users' needs and expectations.

\section{USER-CENTERED DESIGN}

IHTs are designed to enhance health behavior changes and the management of illness, ${ }^{12}$ but their ultimate success depends on whether the intended users (eg, patients) find the applications useful. Usability is defined as the measure of the ease with which a system can be learned and used, including its safety, effectiveness, and efficiency. ${ }^{13}$ User-centered design is an approach for developing applications that incorporates user-centered activities throughout the entire development process. ${ }^{14}$ This approach allows end users to influence how a design takes shape to increase ultimate usability. ${ }^{15}$ It involves a variety of methods, including assessing the intended users, observing and analyzing tasks and requirements, developing and testing prototypes, evaluating design alternatives, analyzing and resolving usability problems, and testing the features and interfaces with users in an iterative manner. Incorporating UCD principles in the overall development of IHTs keeps the focus on meeting users' needs. Once considered dispensable, time-consuming, and costly, evidence of the benefits of the UCD approach is now unequivocal. ${ }^{16-20}$ Research suggests that involving users in the design and development of a new system will improve the system's quality because of the more accurate assessment of user requirements and the higher level of user acceptance. ${ }^{18-21}$ Involving users has been found to substantially reduce development time because usability problems are identified and resolved before the systems were launched. ${ }^{19}$ Applying UCD to the development of IHTs for patients improves functionality and usability, therefore increasing the likelihood of promoting the intended health behaviors and health outcomes.

While UCD is highly acclaimed as a means of ensuring user acceptability, its application with patient- users has not been widely disseminated to the health science disciplines despite calls for its application. ${ }^{10,11}$ This gap is problematic because nurses and other health scientists typically identify the health problems or behaviors of concern and propose possible interventions, many of which are IHTs intended for use by patients.

Why do developers of IHTs designed for patients neglect to incorporate UCD in the development cycle, minimize the significance of evaluating usability with patient-users, or fail to report how the principles of UCD were integrated into the development of their IHTs? Possible explanations include a lack of appreciation for the importance of usability testing, a lack of time and resources to devote to upfront research and development, limited expertise in the principles and techniques of UCD, and perhaps most importantly, the tendency to develop IHTs based on developer-driven needs and priorities rather than those of the intended users. ${ }^{19}$

More than 20 years ago, Gould and Lewis ${ }^{22}$ introduced three guiding principles of UCD: (1) focus on users and tasks early and throughout the design process, (2) measure usability empirically, and (3) design and test usability iteratively. Since then, standards and techniques for applying these principles have emerged to meet the needs of specific projects. ${ }^{17,19,20}$

\section{APPLYING USER-CENTERED DESIGN TO THE DEVELOPMENT OF POCKET PATH}

Using the development of Pocket PATH as an exemplar, we will illustrate how the principles of UCD drove the design and testing of this patient-centered IHT. We developed this IHT to provide lung transplant patients a handheld PC with customized data recording, tracking, messaging, and decision-support programs to promote self-care behaviors, including performing self-monitoring and identifying critical values that need to be to communicated to their transplant team in a timely manner. The complexity of the medical regimen to be followed by patients for the remainder of their lives after lung transplantation can be daunting. The regimen includes selfmonitoring a variety of objective and subjective indicators (eg, home-based spirometry, symptoms, blood pressure, and temperature) because no indicator alone has been shown to adequately detect complications such as acute organ rejection and infection. ${ }^{23,24}$ To this end, patients are expected to measure a variety of health indicators at home and notify the transplant team of any changes in their conditions. ${ }^{25}$ However, many patients find it difficult to adhere to self-monitoring, identify worrisome trends, and decide what values should be reported to the transplant team. ${ }^{26}$ Below is an explanation of how each of the three principles of UCD was applied to the design and testing of Pocket PATH. 


\section{User-Centered Design Principle 1: Focus on Users and Tasks}

\section{ASSEMBLING THE DEVELOPMENT TEAM}

An interdisciplinary team was assembled to ensure that the IHT addressed the latest clinical, behavioral, and computer science advances and standards. It also ensured that multiple perspectives were considered when identifying and resolving issues that might arise during the development of the IHT. The team included a nurse (principal investigator [PI]), computer scientists (human-computer interaction specialist, programming engineer, and user interface designer), behavioral scientists (experts in assessing and intervening on adherencerelated behaviors in transplant and other chronic disease populations), a cardiothoracic transplant physician, and a communication scientist who provided guidance as the project evolved based on his pioneering experience developing IHTs for persons with cancer. ${ }^{6}$

Understanding the patient-users, their characteristics, and the health-related tasks to be performed was the IHT development team's primary concern. Assessing patients actually performing their work enabled us to understand the users' goals, interests, and learning styles that have an impact on the use and effectiveness of an application. Without this knowledge, we could not be certain that the IHT was likely to modify or promote the intended healthrelated behaviors, nor be reasonably certain that the platform we selected and the user interface we designed would be appropriate for the intended patient-users.

\section{ASSESSING INTENDED USERS}

We gathered information about background characteristics for the patients at our center that could affect their use of computer-based technologies from a variety of sources. Similar to the US population of lung transplant patients, ${ }^{27}$ approximately $50 \%$ of our lung recipients are 50 years or older, slightly more than half are female $(53 \%)$, and $93 \%$ are white. Data were not available for computer experience in this cohort, but approximately $15 \%$ of patients used e-mail to communicate with the transplant coordinator (R. Zomak, transplant coordinator, personal oral communication, April 15, 2005). In a recent survey of adult heart transplant patients at our center, ${ }^{28} 35 \%$ (29/82) indicated that they had Web access at home. The proportion of lung transplant patients with some computer skills was anticipated to be similar to that of heart transplant patients; most were novice computer users. Prior research also showed that computer-based interventions were acceptable to chronically ill persons and their caregivers, despite lack of previous computer experience. ${ }^{7,29-31}$ Other studies reported a high degree of acceptance of handheld computers and telephone-based transmission systems ${ }^{32,33}$ by persons with chronic illnesses and low levels of computer literacy, including lung transplant patients. ${ }^{34}$ Although young people find computer technologies readily acceptable and commonplace, older adults have an interest in technology and can acquire new complex computer skills. ${ }^{35}$

To identify any physical impairments that might interfere with patients' ability to use computerized devices, we reviewed the symptoms reported by a large cohort of lung transplant patients. ${ }^{23}$ The prevalence of tremors, blurred vision, and short-term memory loss (primarily adverse effects of the immunosuppression medications) highlighted the need to include users with these impairments in the design and testing of Pocket PATH.

\section{RECRUITING REPRESENTATIVE PATIENTS}

After receiving institutional review board approval, we recruited a sample of seven lung transplant recipientvolunteers from among patients returning to the pulmonary transplant center for routine follow-up. Our sample size was based on prior research suggesting that at least five users will expose most usability problems. ${ }^{36}$ Purposive sampling was used to recruit recipients of both sexes and members of racial and ethnic minorities, as well as participants with blurred vision, tremors, short-term memory impairments, and limited computer experience.

The following eligibility criteria were applied: (1) recipient of a lung transplant at least 12 months ago (to understand and evaluate self-monitoring tasks of patients with experience following the posttransplantation regimen), (2) 18 years or older (children $<18$ years have different self-care patterns because of their developmental stage and dependence on adult guardians), (3) English speaking, (4) living within an hour's drive of the study site (to reduce the time and effort for travel), and (5) willingness to permit a home assessment, attend at least three laboratory testing sessions, test the application in the field setting (his/her home) for a 2-week period, and participate in a final interview and evaluation at the completion of the study. All seven patients approached for participation agreed to enroll. Characteristics of the test users are presented in Table 1.

\section{IDENTIFYING THE INTENDED TASKS}

We reviewed the empirical literature regarding selfmonitoring after lung transplantation to identify the intended tasks. Patients were routinely instructed to monitor clinically significant indicators of potential complications, including temperature, lung volumes, and symptoms. Before discharge from the hospital after transplantation, recipients are given a microspirometer, instructed to measure their lung volumes at least three times a week, record their values on a flow sheet, and 
contact their transplant coordinator if they notice a $10 \%$ reduction in forced expiratory volume in 1 second. They were also instructed to report worsening shortness of breath, cough, or fever.

\section{ASSESSING HOW PATIENTS CURRENTLY PERFORMED THEIR SELF- MONITORING TASKS}

Contextual inquiry methods were used to learn how lung transplant patients were currently carrying out activities related to self-monitoring and to identify how an IHT might support these tasks. The premise for this field interview and observation method ${ }^{37}$ is simply to go where the users perform the tasks, observe, and talk with them as they perform the tasks. Some aspects of contextual inquiry are not foreign to clinicians, who are typically comfortable making home visits and find these visits fruitful for gaining a better understanding of patients' situations and an opportunity to reinforce health behaviors. However, contrary to the usual purpose of home visits during which the clinician is seen as the expert, for contextual inquiry, the purpose is to learn how the users perform the tasks. The stance of the developer is that of an "apprentice," and the users are the "masters" at performing their tasks.

\begin{tabular}{|c|c|}
\hline \multicolumn{2}{|c|}{ Characteristics of Patient-Users $(\mathrm{N}=7)$} \\
\hline Characteristic & No. \\
\hline \multicolumn{2}{|l|}{ Sex } \\
\hline Female & 4 \\
\hline Male & 3 \\
\hline Age, mean (SD) [range], y & $51(11)[21-69]$ \\
\hline \multicolumn{2}{|l|}{ Race } \\
\hline White & 5 \\
\hline African American & 2 \\
\hline \multicolumn{2}{|l|}{ Education } \\
\hline High school & 2 \\
\hline Vocational & 2 \\
\hline College & 3 \\
\hline \multicolumn{2}{|l|}{ Employment } \\
\hline Full-time & 1 \\
\hline Retired & 1 \\
\hline Disabled & 5 \\
\hline \multicolumn{2}{|l|}{ Income, \$ } \\
\hline $5000-19,999$ & 4 \\
\hline $20,000-49,999$ & 2 \\
\hline$\geq 50,000$ & 1 \\
\hline \multicolumn{2}{|l|}{ Impairments } \\
\hline Tremors & 3 \\
\hline Blurred vision & 2 \\
\hline Memory loss & 2 \\
\hline \multicolumn{2}{|l|}{ Computer use } \\
\hline None & 3 \\
\hline Desktop & 4 \\
\hline Desktop and handheld & 2 \\
\hline
\end{tabular}

At the start of the home visit with a lung recipient, he/she was told, "I'm here to learn how you gather and keep track of the information that you consider important for monitoring your health since your transplantation." A selected field note from one home visit is included (see inset) to illustrate what was gleaned about recipients' self-monitoring and communication with the transplant clinician about health changes. Findings of this contextual inquiry conducted in the patient's home, combined with contextual inquiries of other patients, pointed to the need for several customized features to promote self-monitoring. These included the ability to simply and accurately record measures for a variety of objective and subjective indicators, display data in

\section{Contextual Inquiry Field Note}

One recipient took me into her bedroom and pointed to a corner next to her bed with a table that was loaded with what she called "her paraphernalia," which included medication bottles, a spirometer, a glucose meter, a blood pressure cuff, a thermometer, an alarm clock, an address book and a stenographer's notebook. She said, "See, that's how I do it, every morning." I asked her if she would show me what she does every morning while I observe, ask questions, and take notes. She then sat on the side of the bed, took a deep breath, and began what she called her "morning ritual," commenting that, "I do all these things because I know it's important to let [my coordinator] know when things aren't right." She picked up her spirometer first and said, "this is key...if my breathing isn't good, the number will be lower, see (pointing to the digital screen on the microspirometer)." Then, she demonstrated the expiratory maneuver, read the result, and entered the number in her notebook, showing me the many pages of measurements she had entered previously. I asked her what she thought of today's reading; she said it looked pretty good. I asked how she could tell, and she scanned the list of entries over the past several days and said, "by 'eyeballing it,' they look pretty close." I asked what spirometer reading would lead her to contact the coordinator, and she said, "they say to call if the number drops by about $10 \%$...but looking at the list, it's hard to tell when it gets to that point, so I just look for drastic changes...then I guess I'd call...I'd call if it was too low and if I wasn't feeling well. I don't want to bother them otherwise, they're busy enough." I asked her how she judged how well she was feeling, and she said, "I think about whether I'm more winded or whether I can do what I normally do." I asked if there were any other ways for her to tell. She said, “... or if I have a fever or a cough, things they say to call them about, but I have to feel pretty bad to call, otherwise I'll wait and bring it up at my next appointment." I asked what she used the alarm clock for, and she said, "...not too much...sometimes, if I need to get up early for an appointment, or to remind me to take some pills, but most of the time I remember." She showed me her address book with telephone numbers of her transplant coordinator, her physicians, and her pharmacy and contact information of friends and family. 
ways that made it easy for patients to recognize subtle changes and trends, provide warnings when critical thresholds were reached, provide feedback messages reminding patients of changes that coordinators expected to be notified about, organize contact information, and provide reminder systems. The need for these features would not have been apparent without having conducted these face-to-face inquiries with persons who were expected to perform the healthcare tasks in their typical surroundings.

\section{SELECTING THE APPROPRIATE PLATFORM}

Because patients perform self-monitoring in their homes, fully functional, palm-sized, stand-alone computer devices seemed the most logical choice for the IHT application. ${ }^{1,38}$ Handheld devices do not depend on Internet access or require any hardware in the home other than a telephone line. Another consideration was the fact that many lung transplant patients do not reside in close geographic proximity to the transplant center; follow-up visits often require long-distance travel. Therefore, the development of a mobile IHT application was particularly appealing for this patient population. Its portability allowed the device to be taken to the transplant center, where the patients' health information could be shared with their clinicians during follow-up evaluations. We selected the Hewlett Packard iPAQ Pocket PC hx 2000 (Hewlett Packard, Palo Alto, CA) as our platform because it came equipped with several helpful features-calendars, contacts, notes, and alarms. These built-in features were attractive to the users and therefore encouraged use and integration of the device into their normal routines. ${ }^{39}$ The iPAQ uses a version of the Microsoft Windows Operating System (Microsoft, Redmond, WA) and is easily programmable; program updates can be made centrally at the study site and sent via modem to devices remotely. All data entries were time stamped, and data regarding patients' condition and usage of the device were uploaded to the study site via a toll-free telephone line (modem). Flash memory cards made it possible to reinstall the custom programs and save archived data if the system failed or the battery lost power.

\section{User-Centered Design Principle 2: Measure Usability Empirically}

\section{SELECTING USABILITY FACTORS TO EMPIRICALLY MEASURE}

Factors that contribute to overall usability and how each may be measured during usability testing sessions are listed in Table $2 .^{20,40-42}$ The factors should be measured empirically and repeatedly throughout the developmental process. The methods that are used for testing and the criterion values that are used to determine whether each of the factors in Table 2 is met must be established a priori and applied uniformly with all test users. In addition, several reliable and valid selfreport measures are available to assess users' ratings

\section{T a b I e 2}

Usability Factors and Empirical Measurements ${ }^{20,40-42}$

Factors Objective Measures

Learnability: ease with which use of device is learned so users can rapidly accomplish intended tasks

Effectiveness: usefulness for supporting intended tasks

Efficiency: productivity once users have learned the system

Errors: low frequency, severity of errors, and easy recovery

Flexibility: variety of ways to achieve intended tasks

Memorability: ease with which casual users can return to the system without having to relearn

User satisfaction: pleasant for users
Clock time for new users to learn to accomplish the intended tasks

Successful performance of the intended tasks; measures of productivity

Clock time to accomplish the tasks once users have learned the system

Error rates trying to use system; severity of errors; recovery time for errors

Number of different commands or routes to achieve the same goal

Memory failure rate on how to use system the next time; time to relearn the system after periods of nonuse

Frequency for utilization of the system and its features

\section{Subjective Measures}

Users' ratings of the ease and time to learn the system

Users' ratings of the system's ability to promote their performance and productivity

Users' ratings of the system's ability to improve the speed at which they perform

Users' ratings of the impact of errors on using system and their ability to recover from errors

Users' ratings of system's ability to provide different commands or routes to achieve the same goal

Users' ratings of the ability to remember how to use the system the next time and their ability to relearn the system after periods of nonuse

Users' ratings of their fondness, perceptions, and opinions of the system and its features 
regarding such factors as satisfaction, ease, and efficiency over time as the design evolves. ${ }^{43}$

Usability assessment reports, using a predetermined format, were generated for all testing sessions and reviewed by the team. These reports allowed for direct comparisons between users to determine the nature, severity, and frequency of any problems. Quantifying problems in these terms promoted better decisions about which usability problems would be given priority based on available time and resources. Typically, if $50 \%$ or more of participants had difficulty completing a task, then this feature was considered problematic and required attention. ${ }^{44}$ The threshold for modification was lower for some issues, for instance, usability problems that frustrated users or lead them to give up trying to perform a task.

\section{LABORATORY EVALUATION}

Three UCD sessions were conducted in a controlled, laboratory setting to obtain feedback from users on the acceptability and functionality of Pocket PATH. Design iterations were evaluated from the patient-users' perspectives early and repeatedly. For the first usability testing sessions, low-fidelity prototypes, sketches of interface elements on paper or printed screen shots of what the users would see and use, were used to get feedback regarding features such as the appearance of interfaces, syntax of commands, and the performance of simple tasks. Although these initial prototypes did not have all the functionality of the final product, some parts of the design were ready to be tested and could be developed and modified more quickly and inexpensively than the final version. In the process, we obtained feedback from users before we proceeded to the more expensive back-end programming activities. ${ }^{45}$

The human computer specialist students conducted the usability testing, but the PI, primary programmer, and user interface designer observed all testing sessions. This collaboration was useful because we found that the inclusion of experts led to multiple perspectives about recommendations and solutions. The personal contact with the users helped the team stay committed to developing a useful and functional product.

We experimented with videotaping the testing sessions but abandoned this approach for several reasons.
For example, users naturally tilted and repositioned the handheld device and stylus during use, but movement made it difficult to focus the camera on the screen. Additionally, it was not possible to aim the video recorder toward the screen and the user simultaneously. As an alternative to conventional videotaping, we relied on our observations and screen-capturing techniques using Camtasia v2.1 (TechSmith, Okemos, MI) with video and audio capabilities loaded on a laptop and synchronized to wirelessly record how the users made selections and navigated the system's features on the handheld device. This approach allowed the tester(s) to follow the users' paths by viewing the handheld screen images on the laptop. The users were less conscious of being recorded, and both video and audio data were archived for further review and analysis of usability problems. The recordings were automatically time stamped to facilitate tagging issues of concern. The issues and reactions of users could be easily compared, and selected screen images were "cut" using SnagIt v7.2 (TechSmith) software as examples for future inclusion in the usertraining manual.

Users were given scenarios to simulate tasks they would perform at home with the device. They were encouraged to use think-aloud techniques and provide a running commentary of their thoughts while performing the intended tasks. Testing accomplished during session 1 included general device and self-monitoring features using primarily paper or prototype forms; session 2 included adherence and communication functions and any new modifications using the actual programs on iPAQ; and session 3 tested all features and functions. At the completion of each laboratory testing session, we administered a reliable and valid measure of user satisfaction, the After-Scenario Questionnaire (ASQ), ${ }^{46}$ a three-item survey for users to rate their satisfaction with ease, amount of time, and support information on a seven-point scale (lower scores mean more satisfied). An overall ASQ score was obtained by averaging the scores of the three items. Mean ASQ scores (presented in Table 3) declined between sessions 1 (1.76; SD, 0.85) and $3(1.0 ; \mathrm{SD}, 0)$, demonstrating increasing user satisfaction with Pocket PATH over time.

The tapes were reviewed in combination with testers' notes to reveal the potential source of errors and problems

\section{T a b I e 3}

Mean (SD) ASQ Scores After Each Laboratory Testing Sessions ( $=7$ )

\section{Items}

Ease of completing tasks in scenario

Time to complete tasks

Support when completing tasks

ASQ overall

\section{Session 1}

$1.57(0.78)$

$1.43(0.78)$

$2.29(1.3)$

$1.76(0.85)$

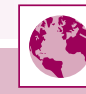

Session 2

Session 3

$1.25(0.5)$

$1(0)$

$1(0)$

$1(0)$

$1(0)$

$1(0)$

$1(0)$

ASQ scores range from 1 to 7 (lower scores mean higher satisfaction). 
to inform future modifications. We rated the significance and priority of each problem and summarized the results using the usability assessment reports. The team discussed all reports and, by consensus, made decisions about future modifications. Using this process iteratively, design features were improved until requirements were met.

\section{User-Centered Design Principle 3: Design and Test Usability Iteratively}

Every stage of UCD includes testing and analysis, and these activities require looping back to earlier stages so that development occurs in iterative cycles of assessingdesigning-testing-analyzing-refining-testing-analyzingrefining. ${ }^{20}$ User-centered design is a way to identify the real needs, reactions, and behaviors of users as they interact with the system over the course of its design iterations until users deem it usable and functional. ${ }^{22}$

\section{FIELD STUDY}

After the laboratory evaluation, Pocket PATH was tested in the field to determine whether patients found it feasible to use independently in their homes and to assess the functionality of all of its features, including data recording, data display, and transmitting data to the study site. Only six of the patients tested Pocket PATH in their homes (the youngest original recipientvolunteer died before the field study). In addition to reviewing training on the use of the device, each patient was given an illustrated user manual describing all the features and a toll-free telephone number to call for technical help. Each user was provided the device, charger, and a CompactFlash modem v90 (Hawking Technology, Irvine, CA) to transmit data to the study site remotely over the telephone line. They were asked to record their measurements-daily spirometry values, blood pressure, pulse, symptom ratings, and others. The results were displayed on the iPAQ screen in both $\log$ and graphical display formats. Normal thresholds were set for each clinical parameter; feedback messages were generated when values outside the acceptable range were entered. Patients were also requested to make any suggestions for improving the user's manual.

The data transmitted to the study site were reviewed to assess utilization of the features defined by the following indices: the percentage of features that users accessed, the number of "hits" per feature, the percentage of daily measurements recorded and transmitted, and times users appropriately contacted their transplant clinicians when prompted to do so by automatic feedback messages. On average, Pocket PATH was used daily by the six participants over the 2-week study period. Each participant used the daily checklist, logs, and graph features regularly. Normal thresholds were set for each clinical parameter, and feedback messages were generated when values fell outside the acceptable range. All of the field test users accessed the message history and notes feature at least once. They also responded to prompts to notify the transplant clinician for signs of potential problems. When the users uploaded data to the study site via the modem, all the data that patients entered into their devices, as well as any feedback messages they received, were flagged upon receipt at the study site. For example, one recipient was entering increasingly higher heart rates from her baseline pulse of 85 beats/min to 100 beats/min over a period of a week. Because the device was programmed to detect increasing trends within a short period, the device appropriately displayed a warning message indicating that she should report her rapid pulse to her transplant clinician. Based on this feedback, she contacted her transplant clinician to discuss proper treatment rather than waiting until her next appointment to report it. In total, the group entered approximately 1400 data values and sent data to the study site at least three times per week. Only one participant used the technical help service; she phoned to make sure that she was uploading her data successfully. One investigatorinitiated call was made to another participant when no data were uploaded for the first 3 days. After reviewing

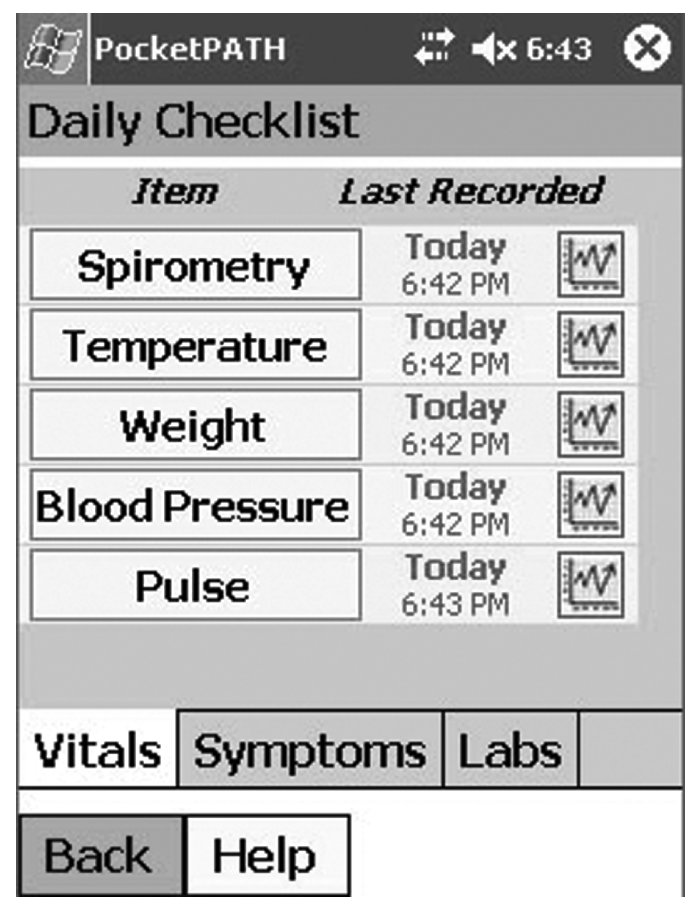

FIGURE 1. The "Daily Checklist" feature of Pocket PATH is composed of screens for patients to enter personal health data (eg, vital signs, symptoms, and laboratory results), with links to graphical display screens. 


\section{T a b I e 4}

\section{PSSUQ Scores After the Field Study $(n=6)$}

Items

1. Easy to use system

Mean (SD)

2. Simple to use system

$1(0)$

3. Effectively complete tasks and scenarios

$1(0)$

$1(0)$

4. Quickly complete tasks and scenarios

5. Efficiently complete tasks and scenarios

$1(0)$

6. Comfort using system

7. Easy to learn to use system

$1(0)$

$1(0)$

8. Believe could become productive using system

9. Error messages were clear.

10. Easily recover from mistakes

11. Information about system was clear.

12. Easy to find needed information

16. Interface was pleasant.

17. Enjoyed using interface

$.05(0.10)$

PSSUQ scores range from 1 to 7 (lower scores mean higher satisfaction).

the procedure with her, we discovered that she had been omitting a step in the active synchronization procedure; her data uploads were successful from then on.

\section{FINAL EVALUATION SESSION}

Following the field study, the six test users returned to the study center to test the final version of Pocket PATH and provide feedback as they evaluated its features (see Figure 1 for one screen shot from the daily checklist feature). At the end of this session, we also administered another reliable and valid measure, the Post-Study System Usability Questionnaire (PSSUQ). ${ }^{47}$ It was specifically designed for use at the completion of usability studies. The PSSUQ assessed overall user satisfaction with 17 aspects of the system and interface, using the same sevenpoint scale as the ASQ (lower scores mean higher satisfaction; possible range, 1-7). The final PSSUQ scores (presented in Table 4) revealed that the test users were highly satisfied with Pocket PATH (mean [SD] scores, $1.05[0.10])$. They also expressed appreciation for the opportunity to be involved in the development process.

\section{SUMMARY}

Pocket PATH is composed of custom features that supplement the standard personal organizer features of the iPAQ, including data entry, graphical displays, reminders, and feedback messages about information considered central for self-monitoring after lung transplant. These behaviors are crucial for lung transplant patients to be actively involved in the interpretation and decision-making processes of tracking their health-related data and communicating changes to clinicians appropriately and promptly.

Keeping our focus on the tasks and users throughout the development process helped reduce the risk of designing an IHT application that was based entirely on what we considered important and useful rather than what the patient-users thought would assist with selfmonitoring activities. We applied the principles of UCD and used a variety of usability-testing techniques to evaluate the effectiveness of screen designs, functions, navigation paths, labels, and other elements of the interface with representative users. Data from iterative testing informed modification and refinement of the application. When the prototype was deemed useful and functional in the laboratory setting, it was further tested in the field.

As other studies have shown, involving users throughout the entire development process ensures that the final IHT is functional and acceptable as soon as it is ready to be deployed. We applied the principles of UCD to involve patient-users in the development of Pocket PATH, therefore increasing the likelihood of enhancing its success in promoting self-monitoring activities after lung transplantation. Based on our results, applying UCD to the development of IHTs intended for use by other patient populations will ensure that users' needs and expectations are met.

We subsequently conducted a randomized controlled pilot trial and determined that newly transplanted patients found Pocket PATH superior to conventional methods for self-monitoring after transplantation. ${ }^{48} \mathrm{~A}$ full-scale randomized controlled trial is now underway to rigorously test the efficacy of Pocket PATH in promoting self-monitoring and to determine the impact of Pocket PATH use on long-term transplant-related health. Furthermore, patients continue to be involved in the ongoing evaluation of Pocket PATH to obtain user feedback regarding the utility and functionality of Pocket PATH overtime.

\section{Acknowledgments}

We extend our thanks to the students, including Jonathan Finger, Lorianne Nault, Lily Cho, and Sean O'Conner, and the lung transplant recipients who participated in the design and testing of Pocket PATH.

\section{REFERENCES}

1. Brennan PF. Telehealth: bringing health care to the point of living. Med Care. 1999;37(2):115-116.

2. Combs SD. Startling technologies promise to transform medicine. Br Med J. 2006;333(7582):1308-1311. 
3. Silva JS, Ball MJ. Prognosis for year 2013. J Am Med Inform Assoc. 2002;66:45-49.

4. Robinson TN, Patrick K, Eng TR, Gustafson DH. An evidencebased approach to interactive health communication: a challenge to medicine in the information age. JAMA. 1998;280:1264-1269.

5. Brennan PF. Characterizing the use of heath care services delivered via computer networks. J Am Med Inform Assoc. 1995;2(3): 160-168.

6. Gustafson DH, Hawkins RP, Boberg EW, et al. CHESS: ten years of research and development in consumer health informatics for broad populations, including the underserved. Int J Med Inform. 2002;65:169-177.

7. Gustafson DH, Hawkins RP, Boberg EW. Impact of a patientcentered, computer-based health information/support system. Am J Prev Med. 1999;16:1-9.

8. Brennan PF, Morre SM, Bjornsdottir G, Jones J, Visovsky C, Rogers M. HeartCare: an Internet-based information and support system for patient home recovery after coronary artery bypass graft (CABG). I Adv Nurs. 2001;35(5):699-708.

9. Kay Bartholomew L, Sockrider MM, Abramson SL, et al. Partners in school asthma management: evaluation of a self-management program for children with asthma. J Sch Health. 2006;76(6):283-290.

10. Institute of Medicine. Crossing the quality chasm: the IOM Health Care Quality Initiative. 2001. http://www.iom.edu/report. asp?id=5432. Accessed June 18, 2007.

11. Gustafson DH, Robinson TN, Ansley D, Adler L, Brennan PF. Consumers and evaluation of interactive health communication applications. The Science Panel on Interactive Communication and Health. Am J Prev Med. 1999;16:23-29.

12. Ahern DK, Kreslake JM, Phalen JM. What is eHealth (6): perspectives on the evolution of eHealth research. J Med Internet Res. 2006;8(1):e4.

13. Preece J, Rogers Y, Sharp H, Benyon D, Holland S, Carey T. Human-Computer Interaction. Workingham, England: AddisonWesley; 1994.

14. Abras C, Maloney-Krichmar D, Preece J. User-centered design. In: Bainbridge W, ed. Berkshire Encyclopedia of Human-Computer Interaction. Great Barrington, MA: Berkshire Publishing Group; 2004:463-468.

15. Lee SH. Usability testing for developing effective interactive multimedia software: concepts, dimensions and procedures. Educ Technol Soc. 1999;2(2):1436-1440.

16. Bias RG, Mayhew DJ. Cost-Justifying Usability: An Update for the Internet Age. San Francisco, CA: Morgan Kaufmann Publishers; 2005.

17. International Organization for Standardization (ISO). Humancentred design processes for interactive systems. ISO 13407:1999 ISO standards. http://www.iso.org/iso/iso catalogue/catalogue tc/ catalogue_detail.htm?csnumber=21197. Accessed May 5, 2007.

18. Mayhew DJ. The Usability Engineering Lifecycle. San Francisco, CA: Morgan Kaufmann; 1999:1-15.

19. Mayhew DJ, Mantei M. A basic framework for cost-justifying usability engineering. In: Bias RG, Mayhew DJ, eds. Cost-Justifying Usability. New York, NY: Harcourt Brace \& Co Publishers; 1994:9-48.

20. Nielsen J. Usability Engineering. New York: Morgan Kaufmann Academic Press; 1993.

21. Kujala S. User involvement: a review of the benefits and challenges. Behav Inf Technol. 2003;22(1):1-16.

22. Gould JD, Lewis C. Designing for usability: key principles and what designers think. Commun ACM. 1985;2(3):300-311.

23. De Vito Dabbs AJ, Hoffman LA, Iacono A, Zullo T, McCurry TR, Dauber JH. Are symptom reports useful for differentiating between acute rejection and pulmonary infection after lung transplantation? Heart Lung. 2004;33:372-380.

24. Teichman BJ, Burker EJ, Weiner M, Egan TM. Factors associated with adherence to treatment regimens after lung transplantation. Prog Transplant. 2000;10(2):113-121.

25. Dew MA, Manzetti JD, Goycoolea JR, et al. Psychosocial aspects of transplantation. In: Smith SL, Ohler L, eds. Organ Transplantation: Concepts, Issues, Practice and Outcomes. New York, NY: MedicaLogic/Medscape; 2002. www.medcape.com.; Accessed September 21, 2007.
26. De Vito Dabbs AJ, Hoffman LA, Swigart V, Happ MB, Dauber $\mathrm{JH}$, Iacono A. Striving for normalcy: symptoms and threat of rejection after lung transplantation. Soc Sci Med. 2004;59(7): $1473-1484$.

27. OPTN. 2006 Annual report of the U.S. Registry of Transplant Recipients and Transplant Data 1988-2003. http://www.optn.org/ latestData/rptData.asp. Accessed July 31, 2007.

28. CT Transplant Group, U. Patient Education After CT Transplantation. Pittsburgh, PA: UPMC; 2002.

29. Gustafson DH, Hawkins RP, Boberg EW, Bricker E, Pingree S, Chan C. The use and impact of a computer-based support system for people living with AIDS and HIV infection. In: Proceedings of the Annual Symposium on Computer Applications in Medical Care. Philadelphia, PA: Hanley \& Belfus; 1994.

30. Lewis D. Computer-based approaches to patient education. J Am Med Inform Assoc. 1999;6:272-282.

31. Street RL, Rimal RN. Health promotion and interactive technology: a conceptual foundation. In: Street RL, Gold WR, Manning T, eds. Health Promotion and Interactive Technology: Theoretical Applications and Future Directions. Mahwah, NJ: Lawrence Erlbaum Associates Inc; 1997:1-18.

32. Finkelstein J, Cabrera MR, Hripcsak G. Internet-based home asthma telemonitoring: can patients handle the technology. Chest. 2000;117(1):148-155.

33. Finkelstein SM, Snyder M, Edin-Stubbe C, et al. Monitoring progress after lung transplantation from home-patient adherence. J Med Eng Technol. 1996;20:203-210.

34. Morlion B, Knoop C, Paiva M, Estenne M. Internet-based home monitoring of pulmonary function after lung transplantation. Am J Respir Crit Care Med. 2002;165:694-697.

35. Ram N, Rabbitt P, Stollery B, Nesselroade JR. Cognitive performance inconsistency: intra-individual change and variability. Psychol Aging. 2005;20(4):623-633.

36. Nielsen J. Estimating the number of subjects needed for a thinking aloud test. Hum Comput Stud. 1994;41:385-397.

37. Beyer H, Holtzblatt K. Contextual Design: Designing CustomerCentered Systems. San Diego, CA: Academic Press; 1998.

38. Moen AB, Brennan PF. Health@Home: the work of health information management in the household $(\mathrm{HIMH})$ : implications for consumer health informatics (CHI) innovations. J Am Med Inform Assoc. 2005;12:648-656.

39. Hawkins RP, Pingree S, Gustafon DH, et al. Aiding those facing health crises: the experience of the CHESS project. In: Street RL, Gold WR, Manning T, eds. Health Promotion and Interactive Technology. Mahwah, NJ: Lawrence Erlbaum; 1997:79-102.

40. Guillemette RA. The Evaluation of Usability in Interactive Information Systems. Norwood, NJ: Ablex Publishing Corp; 1995.

41. Lindgaard G. Usability Testing and System Evaluation: A Guide for Designing Useful Computer Systems. London, England: Chapman \& Hall; 1994.

42. Reed S. Who defines usability? You do! PC Comput. 1992;5(12): 220-232.

43. Arean PA, Alvidrez J, Nery R, Estes C, Linkins K. Recruitment and retention of older minorities in mental health services research. Gerontologist. 2003;43(1):36-44.

44. Rubin J. Handbook of Usability Testing: How to Plan, Design, and Conduct Effective Tests. New York, NY: John Wiley \& Sons Inc; 1994

45. Shaw B, Hawkins R, Pingree S, et al. Creating a dynamic, tailored, online health education and support program for women with breast cancer: a case study of the CHESS program. Paper presented at: International, Communication Association Annual Conference; New York, NY: May 26-30, 2005.

46. Lewis JR. IBM computer usability satisfaction questionnaires: psychometric evaluation and instructions for use. Int J Hum Comp Interact. 1995;7(1):57-78.

47. Lewis JR. Psychometric evaluation of the Post-Study System Usability Questionnaire: the PSSUQ. In: Proceedings of the Human Factors Society 36th Annual Meeting. Atlanta, GA: Human Factors Society; October 12-16, 1992.

48. DeVito Dabbs AJ, Dew MA, Myers B, et al. A pilot-tria evaluation of Pocket PATH: Personal Assistant for Tracking Health after lung transplant. In press. 